\title{
Experimental observations of cohesive sediment dynamics in aquaculture recirculation tanks
}

\author{
J. A. Garcia-Aragon, H. Salinas-Tapia, \\ J. Moreno-Guevara \& V. Diaz-Palomarez \\ Facultad de Ingeniería, Interamericano de Recursos del Agua de la \\ Universidad Autónoma del Estado de México, Toluca, Mexico
}

\begin{abstract}
Cohesive sediments from non-used food and fish excreta are a main concern in aquaculture recirculation tank design. Excess concentrations of sediments can cause fish death or additional costs of energy for aeration. Flow dynamics in these tanks is represented as a multiphase flow with two disperse phases: one of solids (cohesive sediments) and one of gas (oxygen) because aeration is always needed. This research was carried out to understand the settling behavior of flocs when subjected to a liquid shear rate. A reduced scale model of an aquaculture recirculation tank was built in Plexiglas in order to use Particle Image Velocimetry and Particle Tracking Velocimetry techniques to measure fluid velocities, solid settling velocities, floc shape, and size.

The optical techniques provided a description of how the phases organize in space and how this organization is related to the microphysics. Different flow rates and solid concentrations were used to develop varied configurations in the system. Models for floc settling velocity based on fractal theory were calibrated. Cohesive sediments from fish food were observed in long-term experiments at constant fluid shear rate and constant gas flow rates in the recirculation tank. Images were obtained each five minutes. Image analysis provided us with floc settling velocity data and floc size. Using floc settling velocity data, floc density data were obtained for different diameters at equilibrium conditions, after one hour or larger experiments. Statistical analysis of floc velocities for different floc sizes allowed us to obtain an expression for the drag coefficient as a function of floc particle Reynolds number $\left(\mathrm{R}_{*}=\rho_{\mathrm{w}} \mathrm{WsD} / \mu\right)$ where Ws is the floc settling velocity, $\mathrm{D}$ is floc diameter, $\rho_{\mathrm{w}}$ is the liquid mass density and $\mu$ is the liquid
\end{abstract}


viscosity. The results are helpful to improve cohesive sediment removal in aquaculture recirculation tanks by providing a tool to obtain optimum sedimentation rates as a function of fluid shear rates.

Keywords: floc, settling velocity, aquaculture, recirculation tank, fractal dimension, drag coefficient, PTV, PIV.

\section{Introduction}

When water scarcity is a problem, water recirculation systems are a good solution [1]. The reuse of water is the main characteristic of these systems. Most studies of these systems are related to water quality and biology but few to hydrodynamics. In this work we focus on the hydrodynamic characteristics of a circular water recirculation tank.

Efficient solid removal is a main concern in these systems because of the accumulation of non-used food and fish excreta. These solids are generally less than $65 \mu \mathrm{m}$ in diameter and behave as cohesive sediments [2]. These sediments form flocs or aggregates, made of water, inorganic particles and organic particles [3-5]. The method of obtaining adequate settling models for these particles is an open field of research [6].

The most used tanks are circular [7, 8]. Water is supplied in these tanks by the use of diffusers at the walls. In this work a small-scale circular water recirculation tank was used in order to study the solid behavior in the tank. A central settling device was present in order to remove the solids (figure 1). The settling device functions according to the hydrocyclones’ principle [9].

Optical techniques were used in this work: Particle Image Velocimetry (PIV) and Particle Tracking Velocimetry (PTV) [10], to measure fluid and particle velocities, respectively. Polyamide tracers of $5 \mu \mathrm{m}$ in diameter were used to obtain fluid velocities using PIV, and flocs were used as tracers in the PTV technique. PTV also allowed us to measure particle size and shape.

The results were used to calibrate settling velocity models using fractal theory, including an adequate definition of the drag coefficient for permeable flocs. Few experimental data of cohesive sediments are available in the scientific literature [11]. The proposed model is helpful in the design of water recirculation tanks for aquaculture.

\section{Experimental set-up}

A small-scale water recirculation tank made of plexiglass $1.03 \mathrm{~m}$ in diameter and $35 \mathrm{~cm}$ in depth was used in the experiments. A complete system for water recirculation (figure 1) was implemented; diffusers at the wall controlled the flow rate and tank water velocity. The circular flow was generated by diffusers at different levels in the tank wall; water was obtained by a high-rise tank with a constant water level in order to supply by gravity a constant flow rate. A settling device in the center of the tank allowed solid removal. The sediments used were common food for the fish. Preprocessing (screening in a 200 mesh) was needed in order to obtain sizes less than $65 \mu \mathrm{m}$. 


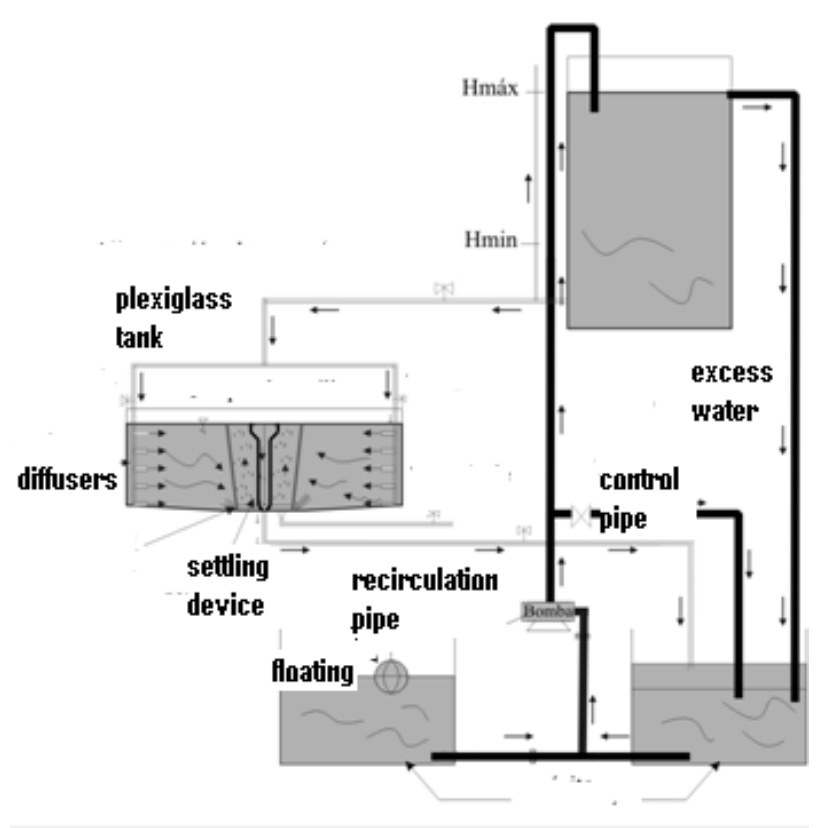

Figure 1: Small-scale circular water recirculation tank.

For the PIV and PTV techniques a $15 \mathrm{~mJ}$ Nd:YAG laser with double cavity (double pulsed) was used. Two CCD cameras, one LUMENERA with 60 fps and resolution $640 \times 480$ pixels and the other JAI with 250 fps and $1600 \times 1400$ pixels were used. Both cameras where equipped with $50 \mathrm{~mm}$ NIKKON lenses. For synchronization a NI-PCIE-1430 card was used.

\section{Methods}

The main difficulty for the proposal of a settling velocity model for flocs is the adequate definition of their density. Many models have been formulated for floc density. The more accepted is the one proposed by Kranenburg [12], as seen in eqn (1).

$$
\rho_{f}-\rho_{w}=\left(\rho_{p}-\rho_{w}\right)\left(\frac{D}{d}\right)^{F-3}
$$

where $\rho_{\mathrm{f}}, \rho_{\mathrm{w}}, \rho_{\mathrm{p}}$ are densities of floc, water and primary particles, $\mathrm{D}$ is the floc diameter and $\mathrm{d}$ is the primary particles diameter. $\mathrm{F}$ is the fractal dimension and the model assumes that the floc is constituted of spherical primary particles of equal diameter. The model can be used for non-spherical particles with equivalent diameters, but in this case the calculation of the fractal dimension becomes difficult. 
To overcome this difficulty in this research we used a different model to fit the experimental data, then we compared both models and were able to obtain the fractal dimension of the experimental flocs. The floc density model used was that of [13], as seen in eqn (2).

$$
\rho_{f}-\rho_{w}=\left(\rho_{p}-\rho_{w}\right) \exp \left(-b D^{c}\right)
$$

where the parameters b and c depend on floc type and shear rate applied [8].

The appropriate values of $b$ and $c$ were obtained with the experimental settling velocity of the sediments used (fish food) when plotted against floc diameter. The best fit to a modified Stokes equation using eqn (2) was performed.

Comparing eqns (1) and (2) a relationship for the fractal dimension $\mathrm{F}$ is obtained.

$$
F=3-\frac{b D^{c}}{\ln \left(\frac{D}{d}\right)}
$$

A balance of drag forces and gravitational forces gives eqn (4).

$$
W_{s}^{2}=\frac{4\left(\rho_{f}-\rho_{w}\right) g D}{3 C_{D f} \rho_{w}}
$$

where $\mathrm{W}_{\mathrm{s}}$ is the floc settling velocity and $\mathrm{C}_{\mathrm{Df}}$ is the permeable particle drag coefficient. Using eqn (1) the following relationship for the settling velocity is obtained in eqn (5).

$$
W_{s}=\sqrt{\frac{4(S-1) g(D)^{F-2}}{3 C_{D f}(d)^{F-3}}}
$$

where $\mathrm{S}$ is the primary particles relative density.

In order to define the drag coefficient in a permeable floc the results of [14] were used for the permeability $\xi$ of a sphere, as seen in eqn (6).

$$
\xi^{-2}=\left[1-\gamma\left(\frac{d}{D}\right)^{3-F}\right]\left(\frac{\left(\frac{d}{D}\right)^{2 F-6}}{\gamma^{2}}-\frac{2\left(\frac{d}{D}\right)^{F-3}}{\gamma}+1\right) \frac{\left(\frac{d}{D}\right)^{2}}{45}
$$

where $\gamma$ is the compaction factor of the floc. From [15, 16] a relationship between the drag coefficient of a permeable sphere and an impermeable one $(\Omega)$ is obtained, as seen in eqn (7). 


$$
\Omega=\frac{2 \xi^{2}\left(1-\frac{\tanh \xi}{\xi}\right)}{2 \xi^{2}+3\left(1-\frac{\tanh \xi}{\xi}\right)}
$$

Assuming that the drag coefficient of the impermeable sphere is $C_{D}=24 / \operatorname{Re}_{\mathrm{p}}$; where $\mathrm{Rep}=\mathrm{W}_{\mathrm{s}} \mathrm{D} / v, v$ is the kinematic viscosity of water. Using eqns (6) and (7) a value of $C_{D f}$ could be obtained.

\section{Results}

The following figures 2-4 show PTV experimental results of settling velocities vs. diameter at different times during a 40-minute experiment. The solid line represents the best fit of a modified Stokes equation that takes into account eqn (2).

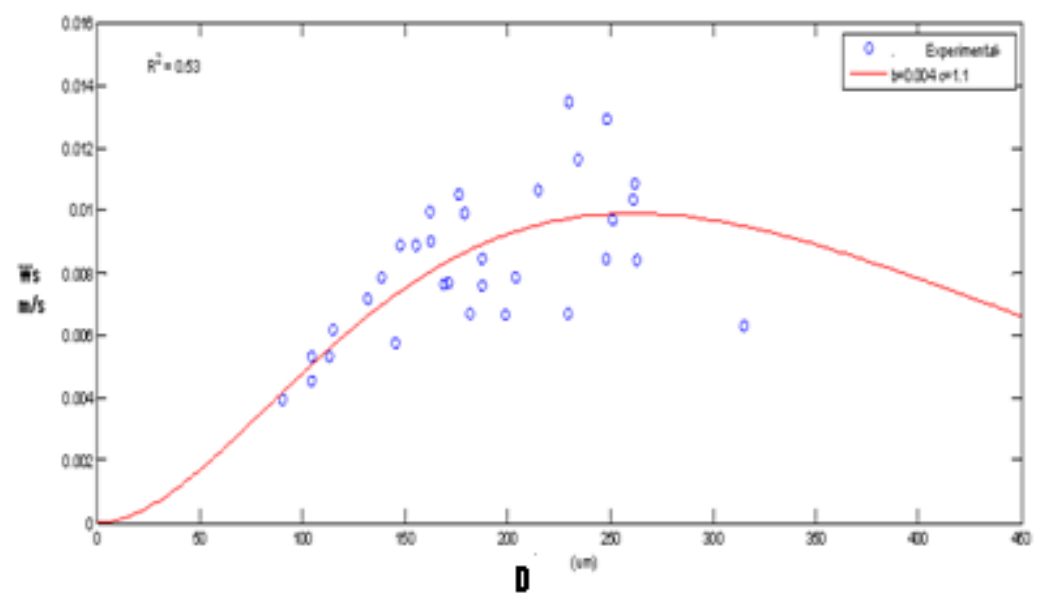

Figure 2: Settling velocities and best fit curve for $\mathrm{t}=10 \mathrm{~min}$.

For all the experimental results the best fit curve was obtained with the values of $b=0.004$ and $c=1.1$ in eqn (2).

With these values of $b$ and c, using eqn (3), the variation of $F$ with $D$ is obtained (figure 5).

With the relationship between fractal dimension and diameter, values of permeability can be obtained for different floc diameters, using eqn (6). A mean 


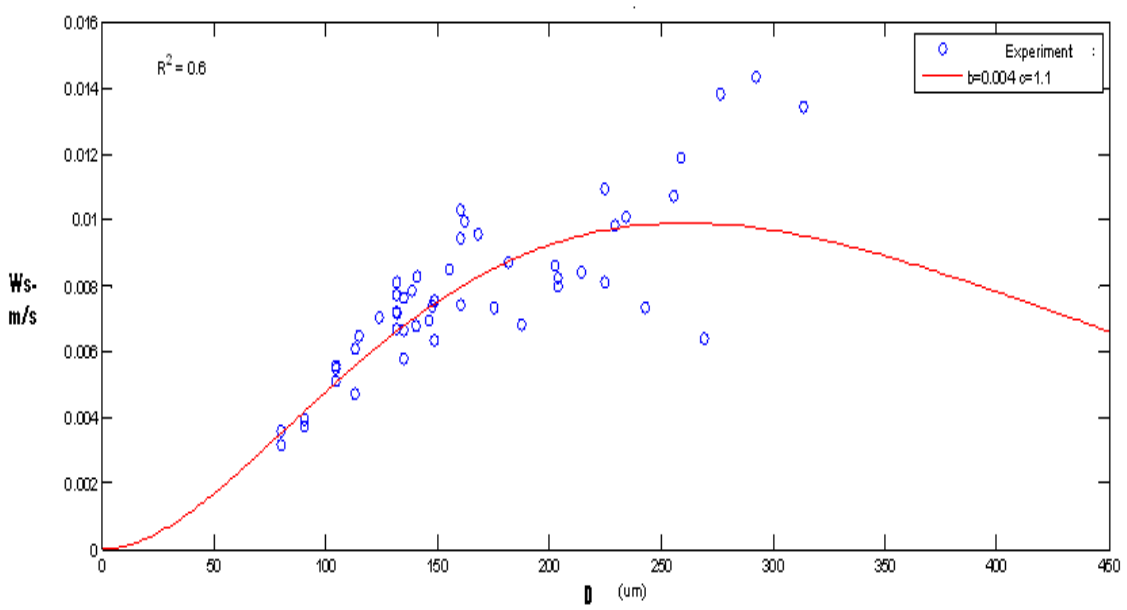

Figure 3: $\quad$ Settling velocities and best fit curve for $\mathrm{t}=20 \mathrm{~min}$.

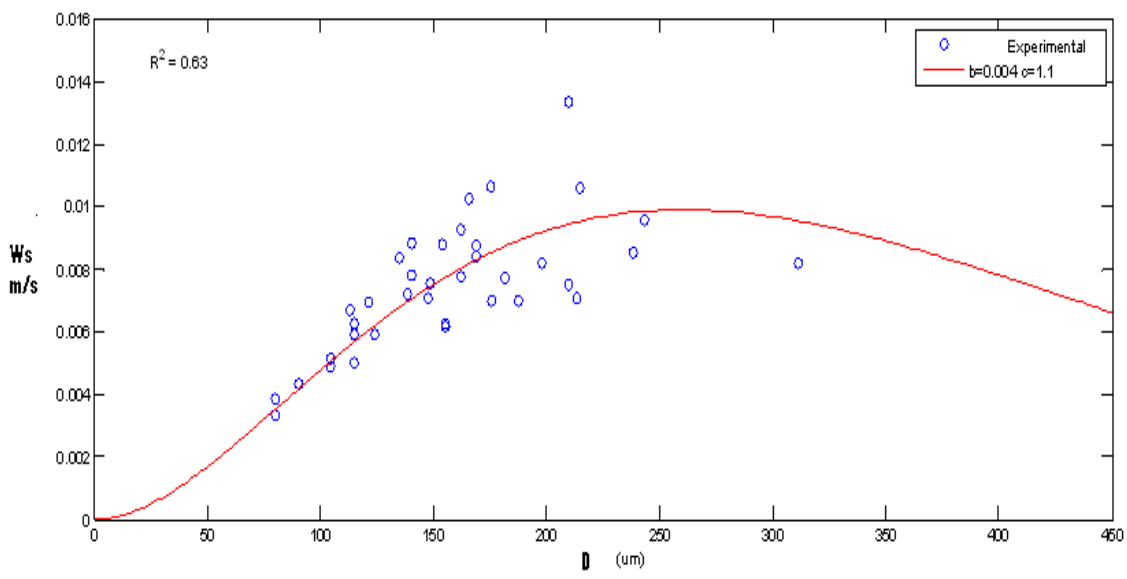

Figure 4: $\quad$ Settling velocities and best fit curve for $\mathrm{t}=30 \mathrm{~min}$.

value of $20 \mu \mathrm{m}$ was obtained using transmission electron microscopy (TEM) for primary particle diameters. Also by means of TEM observations the value of $\gamma$ was defined as 1 , because most of the primary particles are elongated, The drag coefficient for the floc $C_{D F}=\Omega C_{D}$ is obtained using eqn (7).

Plotting $\mathrm{C}_{\mathrm{Df}}$ against $\mathrm{R}_{\mathrm{ep}}$ the following (figure 6 ) was obtained. 


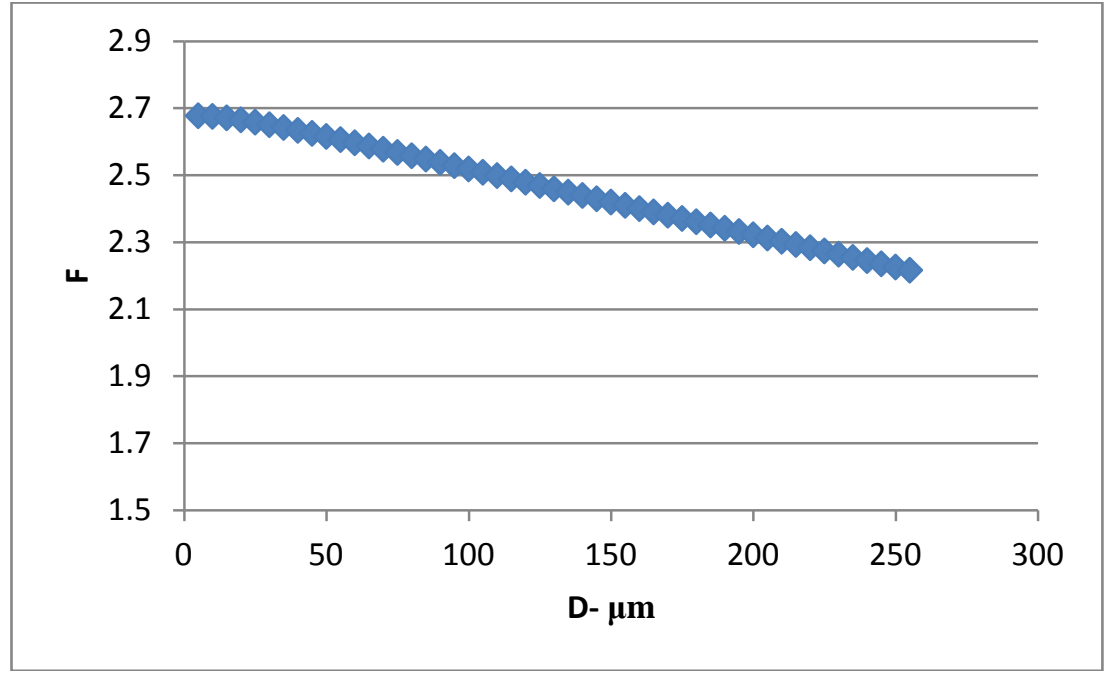

Figure 5: $\quad$ Fractal dimension vs. diameter.

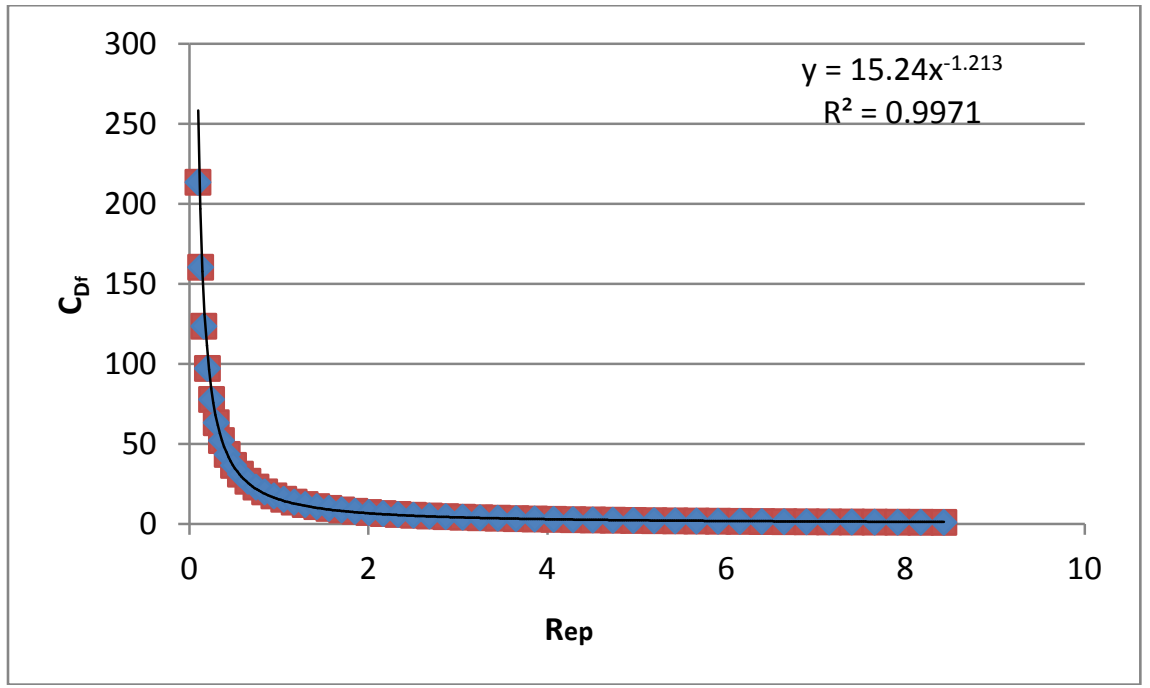

Figure 6: $\quad$ Drag coefficient vs. particle Reynolds number.

A relationship between the drag coefficient and the particle Reynolds number was obtained by cross-correlation, as seen in eqn (8).

$$
C_{D f}=\frac{15.24}{R_{e p}^{1.21}}
$$


Replacing this relationship in eqn (5) the following equation for the settling velocity for food fish was obtained in eqn (9).

$$
W_{s}=\frac{1.276 E+8 \cdot(S-1)^{1.266} D^{1.266 F-1}}{d^{1.266 F-3.797}}
$$

where Ws is in $\mathrm{m} / \mathrm{s}$ and $\mathrm{D}$ and $\mathrm{d}$ in $\mathrm{m}$.

The results show that the drag coefficient of a permeable particle is reduced compared with an impermeable particle of the same diameter as previously stated by Johnson et al. [17]. The contribution of this paper is to develop a methodology to obtain hydrodynamic characteristics of flocs, its fractal dimensions and drag coefficients, from experimental measurements of settling velocities.

\section{Conclusions}

Using optical technique settling velocities, cohesive sediments in a small-scale water recirculation tank were obtained for fish food. The experimental results allowed us to obtain appropriate parameters for a floc density vs. diameter model. Using this model the fractal dimension variation with diameter was obtained. With a balance of gravitational forces and drag forces a model for floc settling velocity was developed. This model contains one undefined parameter: the permeable floc drag coefficient.

Using some relationships between permeable spheres and non-permeable spheres and the experimental results, an appropriate definition of the drag coefficient for fish food was obtained.

The results can be very helpful in the design of aquaculture water recirculation tanks in order to improve solid removal.

\section{References}

[1] Wheaton F.W. Aquaculture Engineering. Wiley - Interscience, New York, 708 pp., 1977.

[2] Droppo I.G. Rethinking what constitutes suspended sediment. Hydrological Processes, 14, 653-667, 2001.

[3] Droppo I.G. and Ongley E.D. Flocculation of suspended sediment in rivers of south-eastern Canada. Water Research, 28, 1799-1809, 1994.

[4] Nicholas A.P. and Walling D.E. The significance of particle aggregation in the overbank deposition of suspended sediment on river floodplains. Journal of Hydrology, 186, 275-293, 1996.

[5] Droppo I.G. Suspended sediment transport-Flocculation and particle characteristics. Encyclopaedia of Hydrological Sciences. Edited by M.G. Anderson. John Wiley \& Sons, Ltd, 2005. 
[6] Garcia-Aragón J., Droppo I., Krishnappan B., Trapp B. and Jaskot C. Experimental assessment of Athabasca River cohesive sediment deposition dynamics. Water Quality Research Journal of Canada, 46(1), 87-96, 2011.

[7] Watten B.J. and Beck L.T. Comparative hydraulics of rectangular cross flow rearing unit. Aquaculture Engineering 6, 127-140, 1987.

[8] Summerfelt S.G., Wilton G., Roberts D., Rimmer T. and Fonkalrsrud K. Developments in recirculating systems for artic char culture in North America. Aquacultural Engineering 30, 31-71, 2004.

[9] Timmons M.B., Summerfeld S.T. and Vinci B.J. Review of circular tank technology and management. Aquacultural Engineering, 18, 51-69, 1998.

[10] Ruhnau P., C. Guetter, T. Putze and C. Schnörr. A variational approach for particle tracking velocimetry. Meas. Sci. Technol., 16, 1449-1458, 2005.

[11] Sundaresan S., Eaton J., Koch D. and Ottino J. Appendix 2: Report of study group on disperse flow. International Journal of Multiphase Flow, 29, 1069-1087, 2003.

[12] Kranenburg C. The fractal structure of cohesive sediment aggregates. Estuarine Coastal Shelf Science, 39, 1665-1680, 1994.

[13] Lau Y.L. and Krishnappan B.G. Measurement of size distribution of settling flocs. NWRI. Publication No. 97-223. National Water Research Institute, Environment Canada, Burlington. Ontario, Canada, 1997.

[14] Rojak S.N. and Flagan R.C. Stokes drag on self-similar clusters of spheres. J. Colloid Interface Sci. 134, 206-318, 1990.

[15] Neale G., Epstein N. and Nader W. Creeping flow relative to permeable spheres. Chem. Eng. Sci. 28, 1865-1874, 1973.

[16] Abade G. C., Cichocki B., Ekiel-Jeżewska M. L., Nägele G. and Wajnryb E. Short-time dynamics of permeable particles in concentrated suspensions. J. Chem. Phys. 132(1), 014503, 2010.

[17] Johnson C.P., Xiaoyan L.I. and Logan B.E. Settling velocities of fractal aggregates. Environ. Sci. Technol. 30, 1911-1918, 1996. 